\title{
Meningkatkan hasil belajar peserta didik dengan menggunakan media Mobile Learning berbasis Ispring Suite 9 pada mata pelajaran kearsipan (PVar Spring)
}

\author{
Aljarotul Nisyah, Mohammad Arief* \\ Universitas Negeri Malang, Jl. Semarang No. 5 Malang, Jawa Timur, Indonesia \\ *Penulis korespondensi, Surel: mohammad.arief.fe@um.ac.id
}

Paper received: 3-5-2021; revised: 24-5-2021; accepted: 28-5-2021

\begin{abstract}
Abstrak
Perkembangan teknologi dalam dunia pendidikan tidak bisa dihindari dan berpengaruh terhadap penggunaan media pembelajaran dalam dunia pendidikan. Hal ini menjadi salah satu tuntutan guru agar dapat berinovasi serta lebih kreatif dalam penggunaan teknologi dalam kegiatan pembelajaran. Oleh karena itu, penelitian ini bertujuan untuk menghasilkan produk media mobile learning berbasis Ispring Suite 9 untuk meningkatkan hasil belajar peserta didik. Produk media pembelajaran yang dikembangkan dilengkapi dengan delapan menu dan fitur yang disusun untuk mempermudah dalam penggunaannya. Ukuran file media hanya 11,5MB yang tidak memakan penyimpanan terlalu banyak. Penelitian dan pengembangan ini menggunakan model Research and Development (R\&D) Borg \& Gall yang telah dimodifikasi sesuai dengan kebutuhan peneliti. Teknik analisis data yang digunakan adalah teknik analisis deskriptif dan teknik deskriptif persentase. Hasil penelitian dan pengembangan ini berupa aplikasi media mobile learning berbasis Ispring Suite 9 pada mata pelajaran Kearsipan khususnya Pemeliharaan Arsip/Preservasi Arsip yang diberi nama PVar Spring. Produk media telah dinyatakan sangat valid dan layak digunakan sebagai media pembelajaran oleh ahli materi, ahli media dan 6 peserta didik uji coba kelompok kecil serta terbukti terdapat perbedaan hasil belajar pada uji coba kelompok besar yang menunjukkan hasil tes kelas eksperimen lebih tinggi daripada kelas kontrol. Sehingga dapat disimpulkan bahwa PVar Spring layak dan efektif untuk meningkatkan hasil belajar peserta didik pada mata pelajaran Kearsipan.
\end{abstract}

Kata kunci: penelitian dan pengembangan; media pembelajaran; mobile learning; ispring suite 9; kearsipan; hasil belajar

\section{Pendahuluan}

Pemanfaatan media pembelajaran sesuai dengan perkembangan teknologi merupakan salah satu bentuk dari pengaruh terhadap dunia pendidikan dan menjadi salah satu upaya agar pengetahuan yang diperoleh menjadi lebih efektif dan efisien (Agbo, 2015; Little, 2013; Pribadi, 2017; Warsita, 2010). Media pembelajaran yang menjadi suatu perantara dalam proses penyampaian materi pada kegiatan pembelajaran, maka perlu dipertimbangkan dengan baik dalam pemilihannya. Pemilihan media pembelajaran yang tepat dan sesuai dengan kebutuhan peserta didik dapat meningkatkan minat belajar peserta didik. Apalagi pada era pandemic covid-19, dimana peserta didik hanya belajar dari rumah saja atau via daring yang mengharuskan untuk memanfaatkan perkembangan teknologi yang ada. Dengan media yang dapat memudahkan peserta didik dalam pembelajaran via daring dapat menjadikan pembelajaran online tersebut tidak menyulitkan peserta didik dalam belajar. Salah satu media pembelajaran yang dapat dimanfaatkan untuk pembelajaran via daring adalah mobile learning.

Pemilihan media berupa mobile learning ini menjadi salah satu upaya agar peserta didik dapat memahami materi yang disampaikan oleh guru. Media yang dikemas menarik serta dapat digunakan pada smartphone dengan layanan yang fleksibel (Darmawan, 2013), sehingga

This work is licensed under a Creative Commons Attribution-ShareAlike 4.0 International License. 
proses belajar pun menjadi lebih efektif meskipun hanya via daring. Proses belajar peserta didik dapat dikatakan efektif apabila peserta didik dapat mendapatkan hasil belajar yang baik, hasil belajar sendiri merupakan suatu perubahan kemampuan peserta didik akibat dari proses pembelajaran (Karwono \& Mularsih, 2018). Selain itu, media mobile learning menjadi salah satu solusi dalam pembelajaran karena dinilai memudahkan dan sangat praktis dalam penggunaannya serta menjadi tantangan pula dari revolusi industri 4.0 (Aripin, 2018; Elfeky \& Yakoub Masadeh, 2016; Firdausi \& Santosa, 2016; Kurniawan, 2017; Little, 2012; Rahmat dkk, 2019; Scholtz dkk., 2017; Shdaifat \& Obeidallah, 2019; Sudarmansyah dkk, 2019; Wulandari dkk, 2019). Mobile learning yang dikembangkan dalam penelitian dan pengembangan ini yaitu mobile learning berbasis Ispring Suite 9 dengan dilengkapi video pendukung materi, gambar, glosarium serta latihan soal. Memanfaatkan software Ispring Suite 9 untuk menghasilkan media pembelajaran mobile learning yang lebih menarik dan dapat dioperasikan pada smartphone untuk menunjang pembelajaran via daring (Churiyah dkk, 2020; Indahini \& Husna, 2018; Jannah dkk, 2020; Praseptiawan dkk, 2018).

Berdasarkan pengalaman peneliti selama melakukan kegiatan Kajian dan Praktik Lapangan (KPL) dan wawancara secara tidak terstruktur yang dilakukan dengan Ibu Alda Yunita, S.M selaku guru mata pelajaran Kearsipan kelas X OTKP SMK Muhammadiyah 7 Gondanglegi. Memperoleh hasil bahwa pada kondisi pandemic covid-19 yang sekarang terjadi, peserta didik hanya belajar melalui via Zoom dan Google Classroom. Kegiatan pembelajaran yang hanya melalui daring, membuat peserta didik menjadi kurang aktif dan tak jarang pula beberapa peserta didik tidak mengumpulkan tugas yang menyebabkan hasil belajar mereka kurang baik. Selain itu, peserta didik masih kesulitan memahami materi Kearsipan hanya melalui slide powerpoint pada pembelajaran via daring sehingga hasil belajar peserta didik masih kurang baik. Berkaitan hal ini, peneliti ingin berinovasi untuk mengembangkan media pembelajaran berupa mobile learning untuk meningkatkan hasil belajar peserta didik.

Berdasarkan penelitian sebelumnya yang sudah dilakukan (Rahmawati \& Mukminan, 2017) menyebutkan bahwa penggunaan mobile learning efektif digunakan untuk mendukung hasil belajar peserta didik. Adapun penelitian lainnya (Alhafidz \& Haryono, 2018; Alshurideh dkk, 2019; Chuchu \& Ndoro, 2019, 2019; Erlinawati dkk, 2016; Martono \& Nurhayati, 2014; Oyelere dkk, 2016; Sibarani dkk, 2019; Surahman \& Surjono, 2017) menyebutkan bahwa mobile learning dapat meningkatkan hasil belajar peserta didik serta membuat pembelajaran menjadi lebih menarik, memudahkan penggunanya, fleksibel dan interaktif.

\section{Metode}

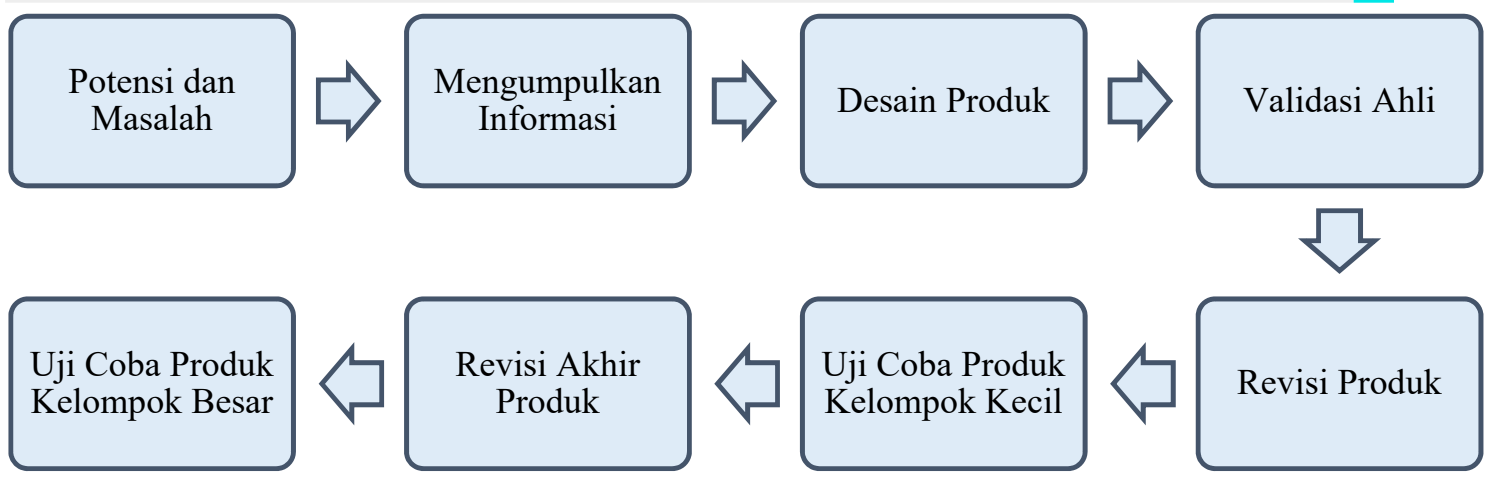

Gambar 1. Langkah-langkah Penelitian 
Penelitian ini menggunakan metode Penelitian dan pengembangan Research and Development (R\&D) dengan model pengembangan Borg \& Gall yang telah dimodifikasi sesuai dengan kebutuhan peneliti menjadi delapan langkah karena keterbatasan waktu, tenaga dan keadaan.

Langkah pertama, menemukan potensi dan masalah yang terjadi selama kegiatan pembelajaran pada mata pelajaran Kearsipan Kelas X OTKP di SMK Muhammadiyah 7 Gondanglegi. Langkah kedua, melakukan pengumpulan informasi agar dapat menyesuaikan dengan apa yang menjadi kebutuhan peserta didik. Langkah ketiga, melakukan desain produk dengan bantuan software Ispring Suite 9. Langkah keempat, melakukan validasi ahli untuk mengetahui kelayakan produk yang berupa mobile learning oleh ahli materi dan ahli media. Langkah kelima, melakukan revisi produk berdasarkan pada saran dan masukan yang diberikan sesuai hasil validasi oleh ahli materi dan ahli media. Langkah keenam, produk diuji cobakan pada kelompok kecil dengan 6 orang peserta didik dari kategori nilai tinggi, sedang dan rendah, setelah diuji cobakan peserta didik diberi angket untuk mengetahui respon peserta didik terhadap produk. Langkah ketujuh, melakukan revisi akhir produk berdasarkan pada saran dan masukan sesuai dengan angket yang telah diisi oleh 6 orang peserta didik dari kelompok kecil. Langkah yang terakhir, uji coba produk kelompok besar dilakukan untuk mengetahui perbedaan hasil belajar peserta didik kelas eksperimen dan kelas kontrol pada ranah kognitif dan psikomotorik.

Jenis data pada penelitian ini menggunakan data kuantitatif dan kualitatif. Data kuantitatif diperoleh dari hasil pengisian angket oleh ahli materi dan ahli media serta nilai peserta didik yang diperoleh pada kelas kontrol dan kelas eksperimen. Sedangkan data kualitatif diperoleh dari catatan maupun masukan berupa kritik dan saran dari validator dan subjek uji coba dari hasil pengerjaan latihan soal pada media yang dilakukan oleh peserta didik. Teknik analisis data yang digunakan adalah teknik analisis deskriptif dan teknik deskriptif persentase

\section{Hasil dan Pembahasan}

Produk yang dihasilkan dari penelitian dan pengembangan ini berupa mobile learning interaktif mata pelajaran Kearsipan pada Kompetensi Dasar 3.9 Menerapkan Pemeliharaan Arsip dan 4.9 Melakukan Pemeliharaan Arsip dan diberi nama PVar Spring (Preservasi Arsip berbasis Ispring Suite). Produk media ini dapat diunduh melalui link http://bit.ly/PVarSpringbyAljarotulNisyah yang kemudian dibuka pada web Google atau mesin pencari lainnya di android. Pengguna harus login email terlebih dahulu untuk dapat mengunduh aplikasi, aplikasi ini pun tidak terlalu membutuhkan banyak ruang karena hanya berukuran 11,5MB. Selain itu, pengguna iOS juga dapat membuka media mobile learning PVar Spring pada mesin pencari melalui link https://cgo3q4onse1m7cvezeztxqon.drv.tw/PVar\%20Spring/PVar\%20Spring\%20(Published)/ tanpa harus mengunduh aplikasinya. Berikut tampilan Home dan penjelasan dari fitur PVar Spring pada menu Bantuan yang telah dikembangkan oleh peneliti: 


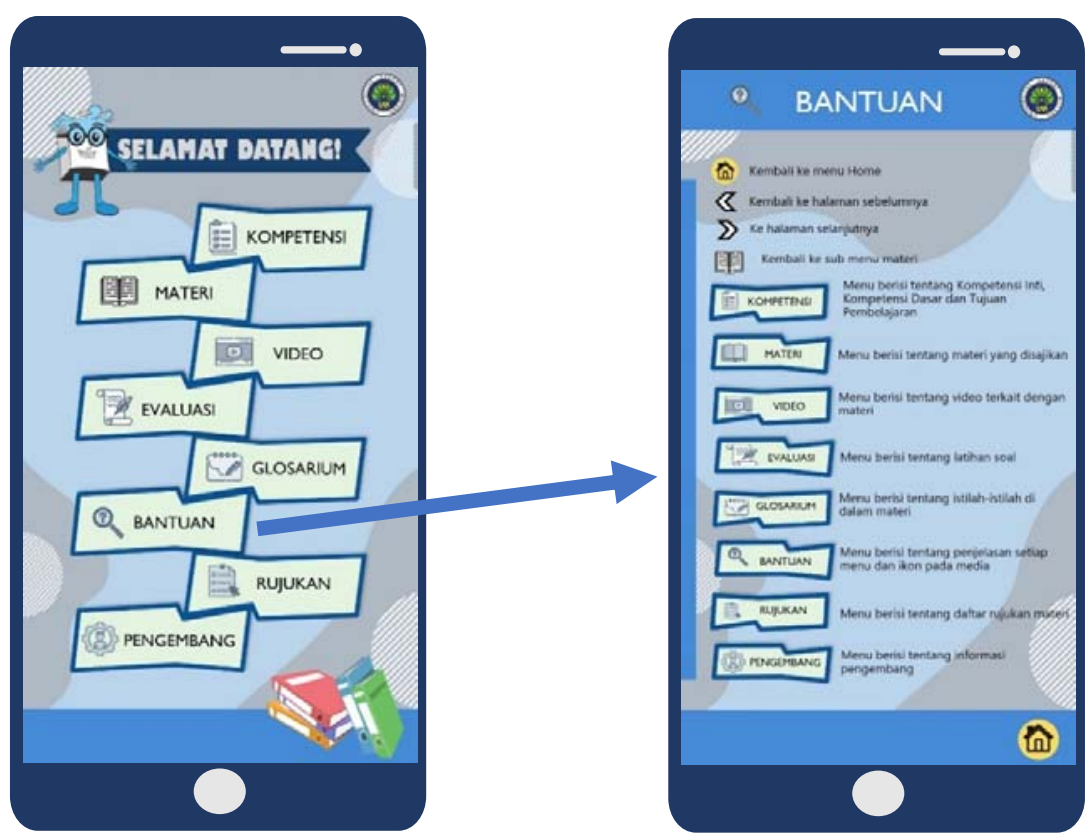

Gambar 3. Halaman Home

Gambar 2. Menu Bantuan

Adapun beberapa tampilan menu dari aplikasi PVar Spring:

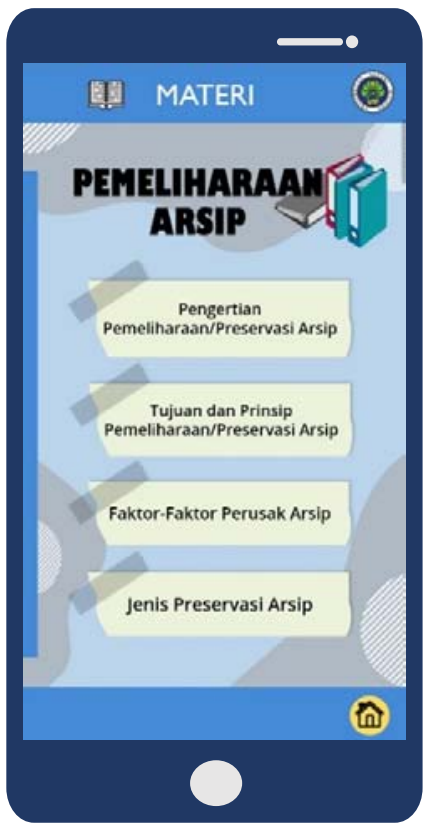

Gambar 5. Menu Materi

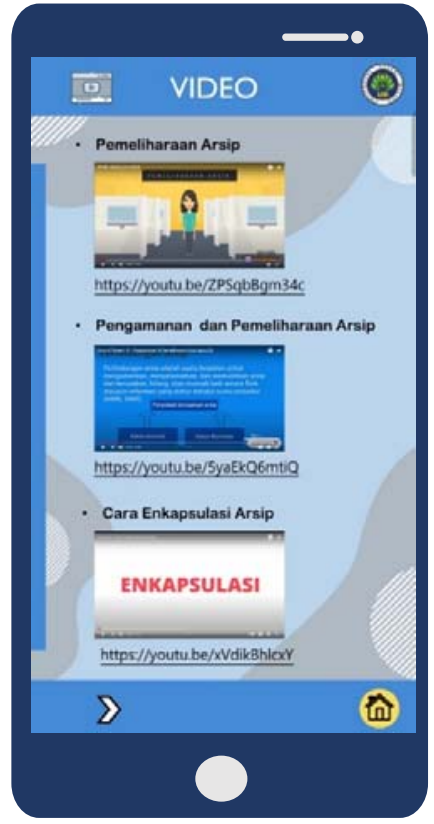

Gambar 6. Menu Video

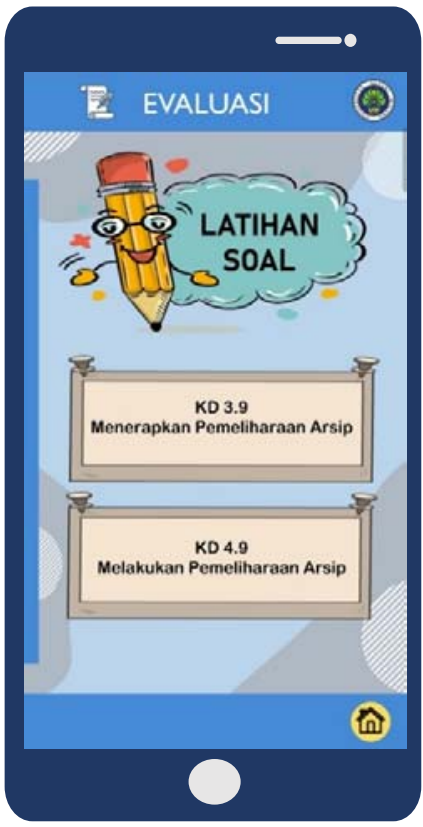

Gambar 4. Menu Evaluasi

Hasil validasi media mobile learning PVar Spring oleh ahli materi, ahli media dan peserta didik uji coba kelompok kecil secara keseluruhan disajikan dalam Tabel 1 berikut: 
Tabel 1. Data Hasil Validasi Keseluruhan

\begin{tabular}{llll}
\hline No & Validasi & Persentase & Keterangan \\
\hline 1. & Ahli Materi & $85 \%$ & Sangat Valid \\
2. & Ahli Media & $98,57 \%$ & Valid \\
3. & Kelompok kecil & $89,58 \%$ & Sangat Valid \\
& Rata-Rata & $\mathbf{9 0 , 6 8 \%}$ & Sangat Valid \\
\hline
\end{tabular}

Berdasarkan Tabel 1, diketahui rata-rata persentase validasi secara keseluruhan didapatkan hasil 90,68\% sehingga dapat dikatakan bahwa media mobile learning berbasis Ispring Suite 9 pada mata pelajaran Kearsipan termasuk kriteria "Sangat Valid" dan layak untuk digunakan sebagai media pembelajaran pada kelas X OTKP SMK Muhammadiyah 7 Gondanglegi. Hal tersebut senada dengan penelitian (Handayani \& Rahayu, 2020; Rochma \& Ibrahim, 2019) yang menyebutkan bahwa berdasarkan validasi media pembelajaran berbasis Ispring Suite dinyatakan sangat valid dan layak untuk digunakan sebagai media pembelajaran. yang interaktif didukung dengan respon positif peserta didik terkait manfaat besar yang didapat dalam memahami materi. Serta media pembelajaran berbasis aplikasi android menggunakan Ispring Suite 9 membuat proses pembelajaran menjadi lebih menyenangkan serta konsep materi lebih mudah dipahami sehingga penggunaan waktu lebih efisien untuk mencapai keberhasilan belajar (Ramadani, 2020).

Tabel 2. Data Hasil Belajar Ranah Kognitif Peserta Didik

\begin{tabular}{llllc}
\hline $\begin{array}{l}\text { Ranah } \\
\text { Penilaian }\end{array}$ & Kelas Eksperimen (OTKP 1) & \multicolumn{2}{l}{ Kelas Kontrol (OTKP 2) } \\
Nilai & $\mathbf{\%}$ & Nilai & \% \\
\hline Kognitif & 86 & $86 \%$ & 62 & $62 \%$ \\
\hline
\end{tabular}

Berdasarkan Tabel 2, diketahui bahwa persentase rata-rata hasil belajar ranah kognitif peserta didik kelas eksperimen yang diambil dari hasil pengerjaan latihan soal dengan menggunakan media mobile learning PVar Spring sebesar 86\%, sedangkan persentase ratarata hasil belajar ranah kognitif peserta didik kelas kontrol yang diambil dari hasil pengerjaan latihan soal dengan menggunakan media slide powerpoint sebesar $62 \%$.

Tabel 3. Data Hasil Belajar Ranah Psikomotorik Peserta Didik

\begin{tabular}{ccccc}
\hline Ranah & Kelas Eksperimen (OTKP 1) & \multicolumn{2}{c}{ Kelas Kontrol (OTKP 2) } \\
Penilaian & Nilai & \% & Nilai & \% \\
\hline Psikomotorik & 87,83 & $87,83 \%$ & 77,66 & $77,66 \%$ \\
\hline
\end{tabular}

Berdasarkan Tabel 3, diketahui bahwa persentase rata-rata hasil belajar ranah psikomotorik peserta didik kelas eksperimen yang diambil dari hasil praktek dengan menggunakan media mobile learning PVar Spring sebesar 87,83\%, sedangkan persentase ratarata hasil belajar ranah kognitif peserta didik kelas kontrol yang diambil dari hasil praktek dengan menggunakan media slide powerpoint sebesar 77,66\%.

Hal ini menunjukkan bahwa hasil belajar peserta didik yang menggunakan media mobile learning berbasis Ispring Suite 9 lebih baik dibandingkan dengan hasil belajar peserta didik yang tidak menggunakan media mobile learning berbasis Ispring Suite 9. Berdasarkan hasil tersebut dapat dikatakan bahwa penggunaan media mobile learning berbasis Ispring Suite 9 efektif digunakan sebagai media pembelajaran yang dapat meningkatkan hasil belajar. Hasil 
tersebut diperkuat dengan penelitian lain oleh (Rahmawati \& Mukminan, 2017) yang menyatakan bahwa mobile learning praktis dan efektif digunakan untuk mendukung hasil belajar peserta didik dalam pembelajaran. Hal ini juga disampaikan oleh (Sibarani dkk, 2019)bahwa penggunaan mobile learning dapat meningkatkan hasil belajar peserta didik yang telah dibuktikan dengan peningkatan hasil belajar peserta didik yang menggunakan media mobile learning.

\section{Simpulan}

Penelitian dan pengembangan ini menghasilkan produk berupa media mobile learning berbasis Ispring Suite 9 yang diberi nama PVar Spring pada mata pelajaran Kearsipan kelas X dengan KD 3.9 Menerapkan Pemeliharaan Arsip dan 4.9 Melakukan Pemeliharaan Arsip di SMK Muhammadiyah 7 Gondanglegi. PVar Spring dapat diunduh melalui link http://bit.ly/PVarSpringbyAljarotulNisyah selain itu untuk pengguna iOS dapat membuka media PVar Spring melalui link https://cgo3q4onse1m7cvezeztxqon.drv.tw/PVar\%20Spring/PVar\%20Spring\%20(Published)/ tanpa perlu mengunduh aplikasinya terlebih dahulu.

Media mobile learning PVar Spring pada penelitian dan pengembangan ini dinyatakan sangat valid dan layak untuk digunakan sebagai media pembelajaran pada mata pelajaran Kearsipan Kelas X OTKP. Hal ini dibuktikan dari hasil validasi oleh ahli materi, ahli media dan uji coba kelompok kecil. Selain itu, media mobile learning PVar Spring terbukti lebih efektif dalam meningkatkan hasil belajar peserta didik berdasarkan pada hasil nilai rata-rata yang diperoleh dari ranah kognitif dan psikomotorik. Media mobile learning PVar Spring cocok digunakan sebagai media pembelajaran via daring, karena lebih fleksibel dapat digunakan kapanpun dan dimanapun sesuai dengan kebutuhan penggunanya.

Media mobile learning PVar Spring pada mata pelajaran Kearsipan yang dikembangkan tidak terdapat kompetensi dasar yang lengkap, sehingga diharapkan peneliti selanjutnya dapat mengembangkan media mobile learning ini mencakup kompetensi dasar satu semester dengan lebih inovatif. Selain itu, video pada media mobile learning berbasis Ispring Suite 9 dapat dibuka secara offline dan tidak hanya berupa link yang hanya bisa dibuka apabila terkoneksi dengan jaringan internet untuk menghemat paket data. Pada latihan soal ditambahkan dengan model HOTS (Higher Order Thinking Skill). Serta hasil dari pengerjaan latihan soal peserta didik yang terintegrasi langsung dengan database guru.

\section{Daftar Rujukan}

Agbo, I. S. (2015). Factors Influencing the Use of Information and Communication Technology (ICT) in Teaching and Learning Computer Studies in Ohaukwu Local Government Area of Ebonyi State-Nigeria. Journal of Education and Practice 6(7), 71.

Alhafidz, M. R. L., \& Haryono, A. (2018). Pengembangan Mobile Learning Berbasis Android Sebagai Media Pembelajaran Ekonomi. Jurnal Pendidikan Ekonomi, 11(2), 118-124.

Alshurideh, M. T., Salloum, S. A., Al Kurdi, B., Abdel Monem, A., \& Shaalan, K. (2019). Understanding the Quality Determinants that Influence the Intention to Use the Mobile Learning Platforms: A Practical Study. International Journal of Interactive Mobile Technologies (IJIM), 13(11), 157. https://doi.org/10.3991/ijim.v13i11.10300

Aripin, I. (2018). Konsep Dan Aplikasi Mobile Learning Dalam Pembelajaran Biologi. Jurnal Bio Educatio, 3(1), 01-09.

Chuchu, T., \& Ndoro, T. (2019). An Examination of the Determinants of the Adoption of Mobile Applications as Learning Tools for Higher Education Students. International Journal of Interactive Mobile Technologies (IIIM), 13(03), 53. https://doi.org/10.3991/ijim.v13i03.10195 
Churiyah, M., Basuki, A., Dharma, B. A., \& Sakdiyyah, D. A. (2020). Mobile Learning Application Berbasis Android : Peran Guru Dalam Pembelajaran Peserta Didik Gen Z \& Alfa. Jurnal Graha Pengabdian, 2(4), 283-295.

Darmawan, D. (2013). Teknologi Pembelajaran. PT Remaja Rosdakarya Offset.

Elfeky, A. I. M., \& Yakoub Masadeh, T. S. (2016). The Effect of Mobile Learning on Students' Achievement and Conversational Skills. International Journal of Higher Education, 5(3), p20. https://doi.org/10.5430/ijhe.v5n3p20

Erlinawati, N. A., Suherman, U., \& Darmawan, D. (2016). Media Pembelajaran Mobile Learning Untuk Meningkatkan Motivasi Dan Kemampuan Praktikum Mahasiswa Stikes Karsa Husada Garut. Pedagogia, 14(2). https://doi.org/10.17509/pedagogia.v14i2.3879

Firdausi, R., \& Santosa, A. B. (2016). Pengembangan Media Pembelajaran Mobile Learning Berbantuan Smartphone Android Pada Mata Pelajaran Perekayasaan Sistem Antena Studi Pada Siswa KELAS XI TAV SMK Negeri 1 Nganjuk. Jurnal Pendidikan Teknik Elektro, 5(1).

Handayani, D., \& Rahayu, D. V. (2020). Pengembangan Media Pembelajaran Interaktif Berbasis Android Menggunakan Ispring Dan Apk Builder Untuk Pembelajaran Matematika Kelas X Materi Proyeksi Vektor. M A T H L I N E Jurnal Matematika dan Pendidikan Matematika, 5(1), 12-25. https://doi.org/10.31943/mathline.v5i1.126

Indahini, R. S., \& Husna, A. (2018). Pengembangan Multimedia Mobile Learning Pada Mata Pelajaran Simulasi Dan Komunikasi Digital Kelas X SMK. Jurnal Kajian Teknologi Pendidikan, 1(2), 141-148.

Jannah, M., Husna, A., \& Nurhalimah, S. (2020). Pembuatan Aplikasi Android Dengan Cepat Menggunakan Ispring Untuk Menunjang Pembelajaran Secara Daring. VEKTOR: Jurnal Pendidikan IPA, 1(2), 66-72.

Karwono, \& Mularsih, H. (2018). Belajar dan Pembelajaran serta Pemanfaatan Sumber Belajar. PT Rajagrafindo Persada.

Kurniawan, H. (2017). Media Pembelajaran Mobile Learning Menggunakan Android (Studi Kasus: Jurusan Sistem Informasi IIB Darmajaya). Explore: Jurnal Sistem Informasi dan Telematika (Telekomunikasi, Multimedia dan Informatika), 8(1).

Little, B. (2012). Effective And Efficient Mobile Learning: Issues And Tips For Developers. Industrial and Commercial Training, 44(7), 402-407. https://doi.org/10.1108/00197851211267983

Little, B. (2013). Issues In Mobile Learning Technology. Human Resource Management International Digest, 21(3), 26-29. https://doi.org/10.1108/09670731311318361

Martono, K. T., \& Nurhayati, O. D. (2014). Implementation Of Android Based Mobile Learning Application As A Flexible Learning. International Journal of Computer Science Issues (IJCSI), 11(3), 168.

Oyelere, S. S., Suhonen, J., \& Sutinen, E. (2016). M-Learning: A New Paradigm of Learning ICT in Nigeria. International Journal of Interactive Mobile Technologies (IJIM), 10(1), 35. https://doi.org/10.3991/ijim.v10i1.4872

Praseptiawan, M., Sujana, D., \& Djuanda, M. (2018). Pengembangan Mobile Learning (M-Learning) STKIP Setiabudhi Sebagai Daya Dukung Pembelajaran Mahasiswa. Produktif: Jurnal Ilmiah Pendidikan Teknologi Informasi, 2, 13-18.

Pribadi, B. A. (2017). Media dan Teknologi dalam Pembelajaran. PT Balebat Dedikasi Prima.

Rahmat, R. F., Mursyida, L., Rizal, F., Krismadinata, K., \& Yunus, Y. (2019). Pengembangan Media Pembelajaran Berbasis Mobile Learning Pada Mata Pelajaran Simulasi Digital. Jurnal Inovasi Teknologi Pendidikan, 6(2), 116-126. https://doi.org/10.21831/jitp.v6i2.27414

Rahmawati, E. M., \& Mukminan, M. (2017). Pengembangang M-Learning Untuk Mendukung Kemandirian Dan Hasil Belajar Mata Pelajaran Geografi. Jurnal Inovasi Teknologi Pendidikan, 4(2), 157. https://doi.org/10.21831/jitp.v4i2.12726

Ramadani, E. M. (2020). Media Pembelajaran Berbasis Aplikasi Android Menggunakan PowerPoint Ispring Suite 9 dengan Model POE2WE pada Materi Teori Kinetik Gas: Literature Review. JPFT Jurnal Pendidikan Fisika Tadulako Online), 8(3).

Rochma, V. A., \& Ibrahim, M. (2019). Pengembangan Media Pembelajaran Berbasis Ispring Suite 8 Pada Materi Bakteri Untuk Siswa Kelas X SMA. BioEdu, 8(2). 
Jurnal Ekonomi, Bisnis dan Pendidikan, 1(5), 2021, 494-501

Scholtz, B., Kapeso, M., \& De Villiers, R. (2017). The Usefulness and Ease of Use of a Mobile Simulation Application for Learning of ERP Systems. South African Computer Journal, 29(2). https://doi.org/10.18489/sacj.v29i2.475

Shdaifat, A. M., \& Obeidallah, R. (2019). Quiz Tool Within Moodle and Blackboard Mobile Applications. International Journal of Interactive Mobile Technologies (IJIM), 13(08), 32. https://doi.org/10.3991/ijim.v13i08.10552

Sibarani, H. P., Komaro, M., \& Sukrawan, Y. (2019). Implementasi Mobile Learning Berbasis Aplikasi Smartphone Untuk Meningkatkan Hasil Belajar Siswa Pada Mata Pelajaran Teknik Pemesinan Bubut. Journal of Mechanical Engineering Education, 6(1), 42-50.

Sudarmansyah, D., Sudjarwo, \& Sinaga, R. (2019). Development of Android-Based Mobile Learning: Answering the Challenges of the Industrial Revolution 4.0. Journal of Education and Practice. 10(14), 1827.https://doi.org/10.7176/JEP/10-14-03

Surahman, E., \& Surjono, H. D. (2017). Pengembangan Adaptive Mobile Learning Pada Mata Pelajaran Biologi SMA Sebagai Upaya Mendukung Proses Blended Learning. Jurnal Inovasi Teknologi Pendidikan, 4(1), 26. https://doi.org/10.21831/jitp.v4i1.9723

Warsita, B. (2010). Mobile Learning Sebagai Model Pembelajaran Yang Efektif Dan Inovatif. Jurnal Teknodik, 14(1), 062. https://doi.org/10.32550/teknodik.v14i1.452

Wulandari, D. A., Wibawanto, H., Suryanto, A., \& Murnomo, A. (2019). Pengembangan Mobile Learning berbasis Android pada Mata Pelajaran Rekayasa Perangkat Lunak di SMK Sultan Trenggono Kota Semarang. Jurnal Teknologi Informasi dan Ilmu Komputer, 6(5), 577. https://doi.org/10.25126/jtiik.201965994 